\title{
Inspection of Pineapple Leaf Fibers Extraction to Be Used in Construction Industry
}

\author{
Kayibanda Patrick ${ }^{1 *}$, Richard Ocharo Onchiri², Geoffrey N. Mang'uriu ${ }^{3}$ \\ ${ }^{1}$ Department of Civil Engineering, Pan African University Institute for Basic Sciences, Technology and Innovation, \\ Nairobi, Kenya \\ ${ }^{2}$ Department of Building and Civil Engineering, Technical University of Mombasa, Mombasa, Kenya \\ ${ }^{3}$ Department of Civil, Construction and Environmental Engineering, Jomo Kenyatta University of Agriculture and \\ Technology Nairobi, Kenya \\ Email: kydpatrick@gmail.com \\ *(ORCID: 0000-0002-1259-7145)
}

\begin{abstract}
This paper presents the possibility of using pineapple leaf fibers (PALF) in construction industry. In this study each leaf of the plant of pineapple contained $2.5 \%$ to $3.5 \%$ of strong white silky fibers. PALF were extracted from the pineapple leaves after harvesting the fruit. An average of the three ages, 1 month, 2 months and 3months was 30 units of pineapple leaves weighed $3 \mathrm{~kg}$ for each age. The reported fiber yield of 1month, 2months and 3months were about $6.64 \%, 7.48 \%$ and $7.70 \%$ of fibers respectively. The extraction of $100 \mathrm{~kg}$ of leaves yielded $6 \mathrm{~kg}$ of the PALF by the process of shredding using the mechanical methods. the reason for overwhelming attention on the natural resources materials are due to large scale agricultural production annually in the world market for example, pineapple is the most cultivated fruits in Africa. Pineapple fruit is cultivated in the world wide approximately land area of 2.2 million $\mathrm{km} 2$. 600 thousand tons of PALF can be extracted from agro waste leaves after harvesting of the fruits, Pineapple leaves are not even suitable for cattle feed and after harvest of fruits the disposal of leaves becomes a serious environmental problem. Therefore this research aim is focused on reducing the waste disposed to landfills by extracting the leaves of pineapple.
\end{abstract}

Keywords: Pineapple leaf fibers, fiber yield, mechanical properties, chemical properties.

\section{Introduction}

Natural fibers have been used to reinforce building materials such as cements, plasters and muds. In the industry of building [1]. The interest in natural fibers is because of the economic and technical aspects including the high insulation properties they poses as compared with other materials [3]. These fibers are classified into non-wood and wood fibers as depicted in Figure 1. Pineapple Leaf Fibers provide several advantages including: they occur in abundance and are of low cost, they pose minimum health risks [2], and have low density, desirable fiber aspect ratio and have relatively high resistance to tension and bending [4]. Furthermore, Pineapple Leaf Fibers have good specific mechanical properties of strength and toughness and lower density than synthetic fibers like glass and carbon or aramid for information, many developing countries trade lignocellulosic fibers for economic improvement [5]. This method also can help the poor farmers as much the support from the country. Other than agricultural propose, the countries growing the Pineapple plant to generate raw materials for industries. The major problem of natural fibers as are in forced material is improper contact of adherent surface and polymer matrix with a bad interaction load transformation from matrix to fiber. Thus, to enhance the adhesion property of fibers, it needs surface modification by using appropriate chemicals. The chemical used, was alkaline treatment [9] grafting with malic anhydride copolymer and using saline coupling agent to treat the PALF. [10]. 


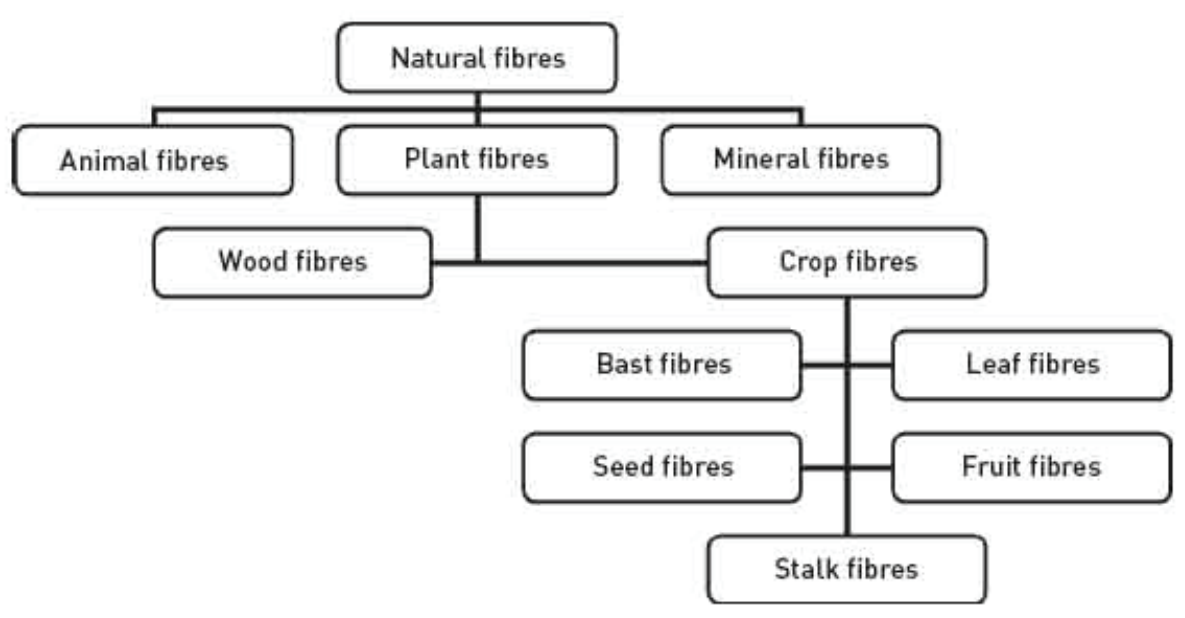

Figure 1. Natural fibers classification.

Pineapple leaf fibers is in types of plant fibers under leaf fibers, they are very common in tropical regions and very simple to extract fibers from their leaves. The utilization of pineapple leaf fiber in composite material is a new source of materials which can be economic, ecofriendly, and recyclable. However, the main issue of PALF is its hydroscopic nature, which makes a big hurdle for fiber utilization as a reinforced material in polymer composites. Surface modification of PALF is required to improve for good interfacial adhesion of PALF with polymers in fabrication of polymer composites.

Some of the main features of PALF as reinforcement materials in composite systems are:

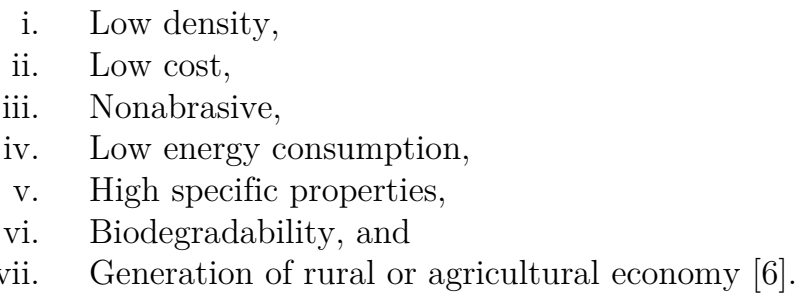

\section{Material and Methods}

\subsection{Materials}

\section{Pineapple Leaf Fibers}

Many researchers worked on the use of the PALF in many fields, but so far the appropriate extraction process of the fibers itself is still not done, therefore This paper presents an appropriate extraction of leaves from the pineapple leaves agro waste. The study of chemical, mechanical and physical properties of PALF composites revealed that their properties are highly depend on geographic origin of fibers, climatic growth conditions and processing techniques [7].

The use of pineapple leaf fibers will not only replace or substitute the expensive synthetics fiber, but also it improves mechanical performances of the construction materials, [8]. Among different types of natural fibers, PALF shows outstanding fiber properties which are rich in cellulose, cost effective, ecofriendly having good fiber strength. Pineapple leaf fiber is one of Natural fibers like sisal, banana, jute, oil palm, kenaf and coir that has been used as reinforcement in thermoplastic composite and civil engineering structures. [11].

\subsection{Methods}

The mechanical method was used for the extraction as shown in figure 2 and it is faster and able people to make it like a commercial product; the manual method is not faster like mechanical method and it 
requires more labors. The pineapple leaf fibers were dried under the sun for two days. From production of fibers, there were three states in this study. The first was the state of the fiber is wet fiber, the second dried fiber and the third usable fiber. When fibers were freshly extracted from original leaves, they contain moisture and the state is wet fiber. The dried fibers is when the fibers were dried under sunlight or certain temperature after extracted from their leaves. Furthermore, the usable fiber is the total dried fibers were to be used. From each type of pineapple leaves divided into three ages which were 1 month, 2 months and 3 months. A special machine with feed roller, leaves scratching roller and serrated roller used to scratch

Out the waxy layer at the same time breaking the leaf surface for ease of extracting the PALF, after removing the top waxy layer, fibers were extracted from pineapple leaves. After extraction, and dry period, Alkali Treatment was done to improve the interfacial adhesion by using $\mathrm{NaOH}$ concentration with various concentrations of $\mathrm{NaOH} 3 \%, 5 \%$ and $7 \%$ for 1 hour at $80^{\circ} \mathrm{C}$. [12]

The fiber yield was evaluated to determine which time period of drying can give a good results of production to be implemented in future.

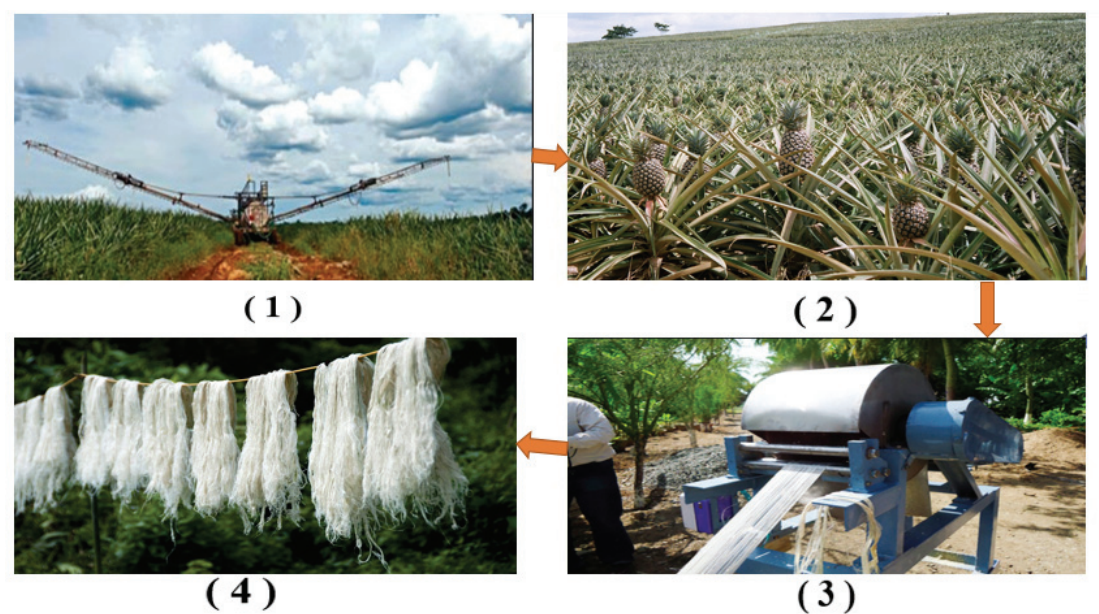

Figure 2. Extraction process of PALF

(1) The field of pineapples

(2) The leaves and fruits of pineapples

(3) The Extraction of pineapple leaves

(4) Pineapple leaf fibers

\section{Results and Discussion}

\subsection{Fiber Yield Properties of Pineapple Leaf Fibers}

Mechanical methods was done this way, each leaf of the plant of pineapple contained $2.5 \%$ to $3.5 \%$ of strong white silky fibers. Pineapple Leaf Fibers (PALF) were extracted from the pineapple leaves after harvesting the fruits. Fiber yield percentage was calculated to determine which type of pineapple leaf produce high production of dry fiber.

An average of the three ages of drying period of 1 month, 2 months and 3 months was 30 pieces of pineapple leaves weighed $3 \mathrm{~kg}$ for each age. The reported fiber yield of 1month, 2 months and 3 months were about $6.64 \%, 7.48 \%$ and $7.70 \%$ of leaves respectively. The extraction of $100 \mathrm{~kg}$ of leaves yielded 5 $\mathrm{kg}$ of the pineapple leaf fibers by the process of shredding using the mechanical methods. The fiber yield calculation helped to determine which age that produced the highest percentage of fiber yield. Percentage Yield of Pineapple Leaf Fibers was calculated by using the following equation (1).

$$
\% \text { of F.Y }=\frac{\text { Weight of dry PALF }(\mathrm{kg})}{\text { Weight of fresh pineapple leaves }(\mathrm{kg})} \times 100 \%
$$


Each age, i.e. drying period of 1 month, 2 months and 3 months was done in three trials, and the mean was taken and in order to get the accurate production.

Table 1. The fiber yield calculation

\begin{tabular}{|c|c|c|c|c|c|}
\hline Months & Samples & wt of fresh PALF (kg) & wt of dry PALF $(\mathrm{kg})$ & fiber yield & Mean of F.Y (\%) \\
\hline \multirow{3}{*}{1 month } & 1 & 3 & 0.197 & 6.57 & \multirow{3}{*}{6.64} \\
\hline & 2 & 3 & 0.199 & 6.65 & \\
\hline & 3 & 3 & 0.200 & 6.68 & \\
\hline \multirow{3}{*}{2 months } & 1 & 3 & 0.209 & 6.99 & \multirow{3}{*}{7.48} \\
\hline & 2 & 3 & 0.228 & 7.60 & \\
\hline & 3 & 3 & 0.235 & 7.85 & \\
\hline \multirow{3}{*}{ 3months } & 1 & 3 & 0.218 & 7.29 & \multirow{3}{*}{7.70} \\
\hline & 2 & 3 & 0.234 & 7.8 & \\
\hline & 3 & 3 & 0.240 & 8.01 & \\
\hline
\end{tabular}

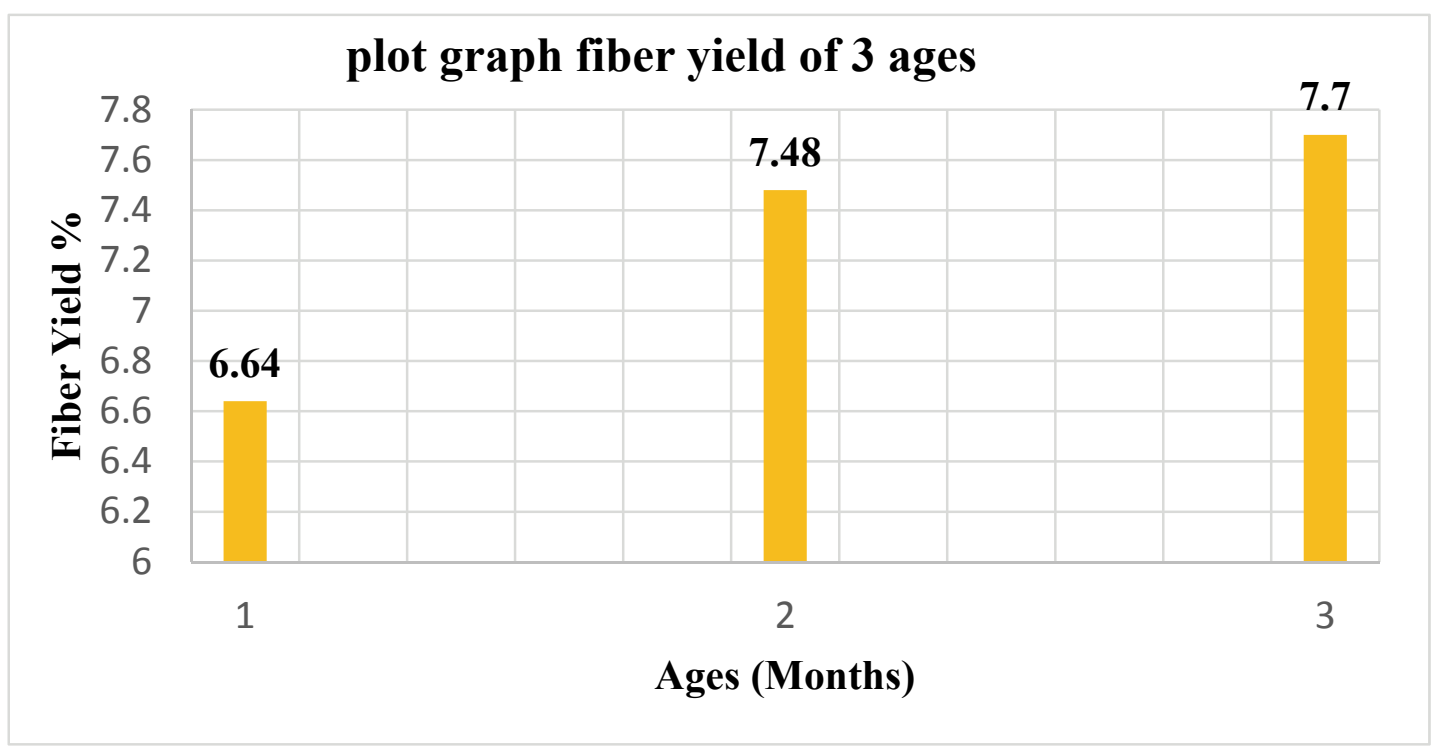

Figure 3. Fiber yield of three ages

According to figure 3, the highest fiber yield percentage was $7.70 \%$ for 3 months and it was observed that as the period get increased, as compared to the higher fiber yield percentage is achieved as shown in figure 3.

\subsection{Physical Properties of Pineapple Leaf Fibers}

The Tensile test was done to measure the extent to which the PALF can elongate to the breaking point. It was needed for determining the maximum force was required to break the fiber or specimen sample. Furthermore, samples were divided into different age such as 1 month, 2 month and 3 months. For the test to be accurate, 9 pieces of pineapple leaves are used. The standard used for the testing was based on American Standard Testing Methods (ASTM C1577-03). 


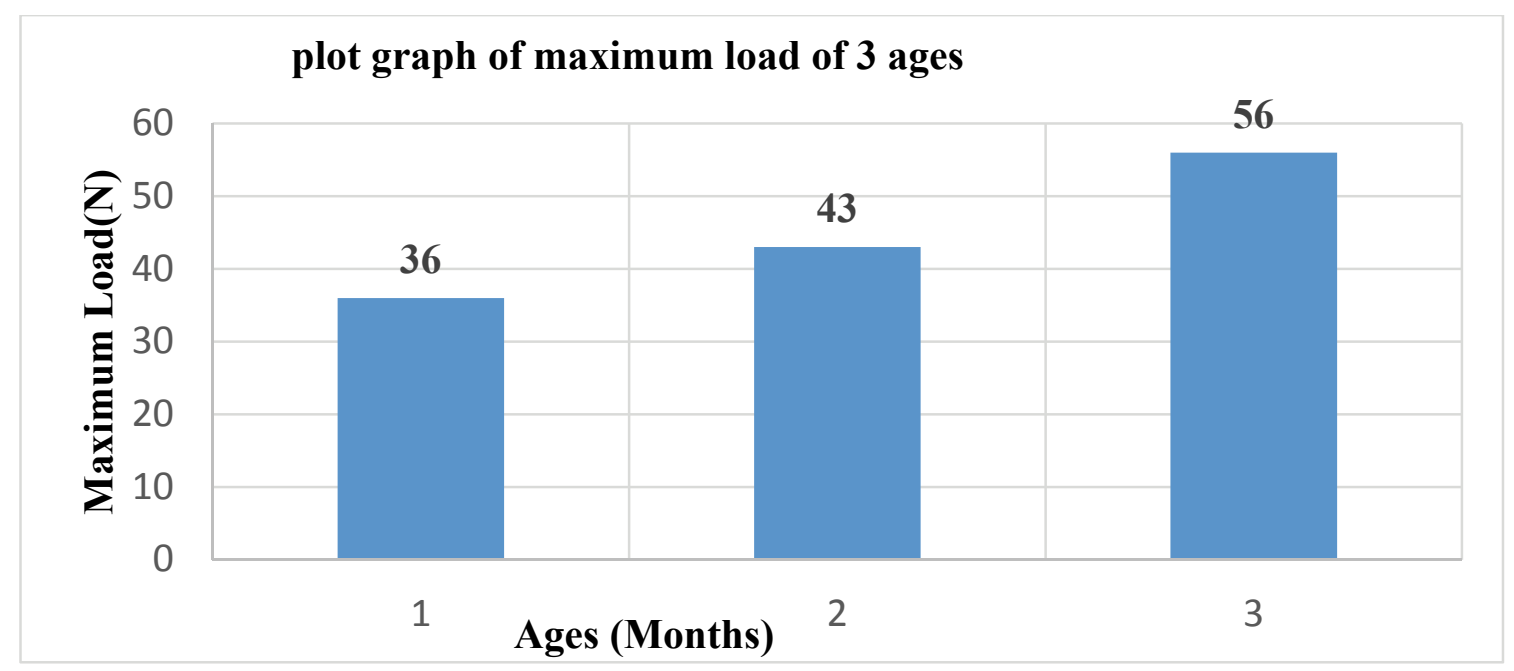

Figure 4. Maximum load comparison for different ages

According to figure 4 it was observed that the maximum load got increased as the period got increased, the higher maximum load was $56 \mathrm{~N}$ for 3 months. The longer time required for drying, the higher maximum loads.

\subsection{Chemical Properties of Pineapple Leaf Fibers}

Chemical constituents of Pineapple Leaf Fibers, which are cellulose, hemicelluloses and lignin were determined following the ASTM D854-9, the samples of PALF were cut in equal length of $30 \mathrm{~mm}$ and diameter of $0.052 \mathrm{~mm}$.

Wt. $\mathrm{A}=$ weight after $12 \mathrm{~h}$ of even dry $40^{\circ} \mathrm{C}$ using $\mathrm{C}_{2} \mathrm{H}_{5} \mathrm{OH}$

Wt. $\mathbf{B}=$ weight after $12 \mathrm{~h}$ of even dry $80^{\circ} \mathrm{C}$ using $\mathrm{KOH}$

Wt. $\mathrm{C}=$ weight after $12 \mathrm{~h}$ of even dry $80^{\circ} \mathrm{C}$ using $\mathrm{H}_{2} \mathrm{SO}_{4}$

Table 2. Chemical properties of PALF

\begin{tabular}{llllllllll}
\hline sample & smp wt & glass wt & glass + smp & wt. A & wt. B & wt. C & cellulose & hemicellulose lignin \\
\hline A & 1.007 & 31.7241 & 32.7311 & 32.8743 & 32.5838 & 32.2444 & 33.704 & 28.8 & 32.2444 \\
B & 1.009 & 31.9 & 32.9712 & 33.1588 & 32.8394 & 32.4612 & 37.483 & 31.6 & 32.4612 \\
C & 1.004 & 31.3 & 32.3067 & 32.5025 & 32.2354 & 31.9047 & 32.898 & 26.6 & 31.9047 \\
\hline & & & & & mean & $\mathbf{3 4 . 6}$ & $\mathbf{3 0 . 2}$ & $\mathbf{3 2 . 3}$ \\
& & & & & stdev & $\mathbf{2 . 6 7}$ & $\mathbf{2 . 5 1}$ & $\mathbf{0 . 2 8}$ \\
\hline
\end{tabular}

Source: The chemical properties (i.e., proportions of cellulose, hemicellulose and lignin) of the treated four fibers samples were determined based the procedure described by Direct method of cellulose, hemicelluloses and lignin [13] [14].

Table 3. NaOH concentration of PALF

\begin{tabular}{lllll}
\hline Mechanical & \multicolumn{4}{c}{$\boldsymbol{\%}$ of $\mathbf{N a O H}$ concentration } \\
\cline { 2 - 5 } properties & $\mathbf{0 \%}$ & $\mathbf{3 \%}$ & $\mathbf{5 \%}$ & $\mathbf{7 \%}$ \\
\hline Tensile Strength & $23.5 \mathrm{MPa}$ & $25.9 \mathrm{MPa}$ & $30.1 \mathrm{MPa}$ & $35.8 \mathrm{MPa}$ \\
Flexural Strength & $32.1 \mathrm{MPa}$ & $33.7 \mathrm{MPa}$ & $40.0 \mathrm{MPa}$ & $48.6 \mathrm{MPa}$ \\
Elongation at break & $15.11 \%$ & $18.94 \%$ & $20.48 \%$ & $24.93 \%$ \\
Young's modulus & $601.3 \mathrm{MPa}$ & $813.5 \mathrm{MPa}$ & $1130.4 \mathrm{MPa}$ & $1503.8 \mathrm{MPa}$ \\
\hline
\end{tabular}


Alkali Treatment was done on the dry Pineapple leaf fibers using three different percentage of $\mathrm{NaOH}$ concentration, $3 \%, 5 \%$ and $7 \%$ for 2 hours at $80^{\circ} \mathrm{C}$ to remove the unwanted soluble cellulose, hemi cellulose and lignin as shown in table 3. From The fiber to solution weight ratio was maintained at 1: 20. After 2 hours the fibers were washed thoroughly in distilled water to remove excess of $\mathrm{NaOH}$ and dried at $60^{\circ} \mathrm{C}$ for 24 hours[15] [16] [17] [18].

\subsection{Tensile Strength of Concrete with PALF}

The Splitting Tensile Strength at $0.2 \%, 0.4 \%, 0.6 \%, 0.8 \%$ and $1 \%$ of PALF per cement weight increased with curing time at 28 days at each percentage had a larger splitting tensile strength value than those at 7 days and 14 days curing. There was a significant increment in the tensile strength values at $1 \%$ PALF for 7 days, 14 days and 28 days curing times. There were percentage increment of 4.61\%, 22.76\%, 27.29\%, $36.60 \%$ and $69.61 \%$ for $0.2 \%, 0.4 \%, 0.6 \%, 0.8 \%$ and $1 \%$ PALF additions respectively were obtained as compared to the control mix at 7 days curing time, where $3.15 \%, 16.07 \%, 23.76 \%, 39.45 \%$, and $54.19 \%$ for $0.2 \%, 0.4 \%, 0.6 \%, 0.8 \%$ and $1 \%$ PALF additions respectively were obtained as compared to the control mix at 14days testing, where $2.73 \%, 8.45 \%, 15.43 \%, 30.37 \%$, and $51.62 \%$ for $0.2 \%, 0.4 \%, 0.6 \%$, $0.8 \%$ and $1 \%$ PALF additions respectively were obtained as compared to the control mix at 28 days of curing time. Figure 5 shows graphically an improvement in the tensile strength as the percentage of PALF were added therefore incorporation of fibers in the concrete can also improve first crack strength and ultimate ductility index.

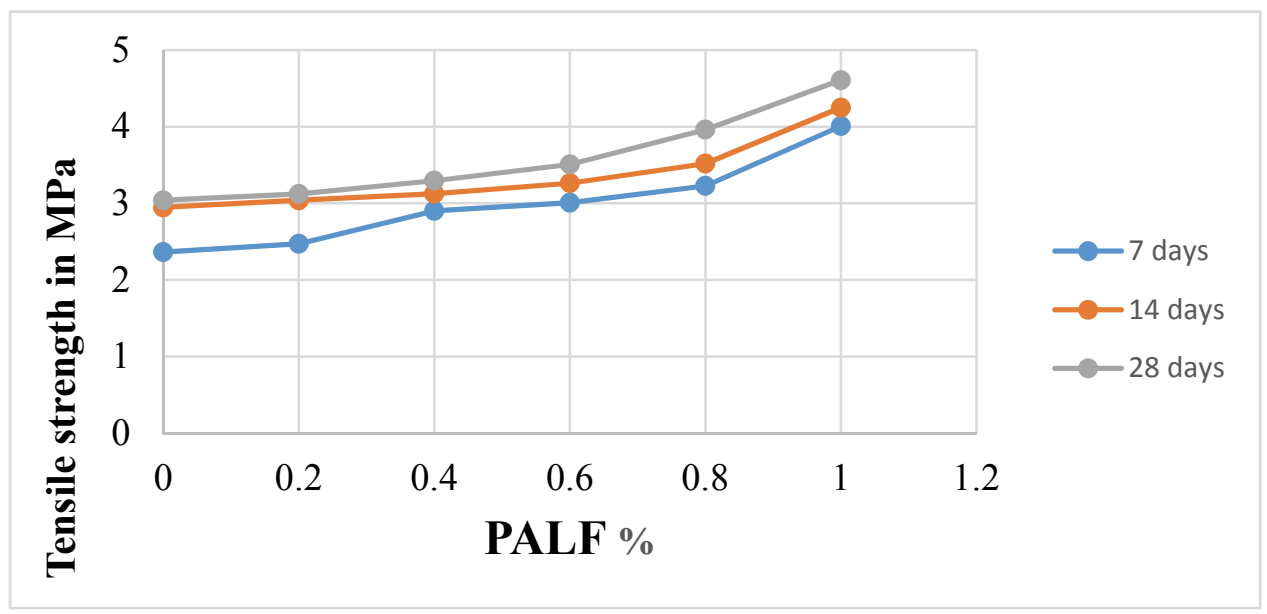

Figure 5. Effect of PALF on the splitting tensile strength of concrete.

\section{Conclusion}

1) Based on experimental work, it was concluded that the longer the period of drying the pineapple leaves, the higher yield of fibers was observed as the time increases.

2) According to the tensile test, it was found that the PALF becomes stronger as the time period of the dry process get increased.

3) The results have shown that PALF can potentially be considered as candidate materials for structural applications, offering desirable and excellent mechanical properties.

4) From the socio economic prospective, PALF is a new source of raw material to the industries and can be potential replacement of the expensive and non-renewable synthetic fiber.

5) Mechanical properties i.e. tensile strength, flexural strength, elongation at break \&young's modulus of alkali treated PALF are improved compared to the untreated PALF \&it was also found that, they increased with the increasing of $\mathrm{NaOH} \%$ of concentration.

6) Tensile strength of concrete was improved in concrete, therefore this material can be used in construction industry. 
Acknowledgements. The authors with great pleasure thank the administration of Pan African University, Institute for Basic Sciences, Technology and Innovation, Department of Civil and Construction Engineering for providing their valuable assistance in the inspection of Pineapple leaf fibers extraction.

\section{References}

1. Hejazi, S. M., Sheikhzadeh, M., Abtahi, S. M., \& Zadhoush, A. (2012). A simple review of soil reinforcement by using natural and synthetic fibers. Construction and Building, Page13.

2. Mashitah Binti Razi. (2011). Effect of Pineapple Leaf Fiber Length on the Properties of Pineapple Fiber Starch Composites. Faculty of Mechanical Engineering Universiti Teknikal Malaysia Melaka, (June) Page 4.

3. Steve W. Taylor, Allan L. Carroll, Rene I. Alfaro, and Les Safranyik (2006). Chapter 2 - Forest, Climate and Mountain Pine Beetle Outbreak Dynamics in Western Canada, in book: The mountain pine beetle: a synthesis of biology, management and impacts on lodgepole pine, Canadian Forest Service.

4. Buitrago, B., Jaramillo, F., \& Gómez, M. (2015). Some Properties of Natural Fibers (Sisal Pineapple, and Banana) in Comparison to Man-Made Technical Fibers (Aramide, Glass, Carbon). Journal of Natural Fibers, 12(4), Page 357-367.

5. Quijano-solis, C. J. (2015). Study of Natural Fiber Breakage during Composite Processing. Faculty of Forestry University of Toronto Page 6.

6. (Mishra, K., Deepak, V., Siddharth,J., Xiaolei,Z., Prakash, C.G.2004). Green approaches to biocomposite materials science and engineering Page 15.

7. Repon, R., Motaleb, K. Z. M. A., Islam, M. T., Mamun, R. Al, \& Mithu, M. R. (2017). Tensile and Water Absorption Properties of Jute and Pineapple Fabric Reinforced Polyester Composite. International Journal of Composite Materials 2017, 7(2): 72-76, 7(2),72-76. https://doi.org/10.5923/j.cmaterials.20170702.04

8. Wahyuningsih, K., Iriani, E. S., \& Fahma, F. (2016). Utilization of cellulose from pineapple leaf fibers as nanofiller in polyvinyl alcohol-based film. Indonesian Journal of Chemistry, 16(2), 181-189. https://doi.org/ 10.14499/ijc-v16i2p181-189

9. A. K. Mohanty, M. A. Khan, and G. Hinrichsen, "Influence of chemical surface modification on the properties of biodegradable jute fabrics - polyester amide composites, "Composites Part A: Applied Science and Manufacturing, vol.31, no.2, pp.143-150, (2000).

10. M.Abdelmouleh, S.Boufi, M.N.Belgacem, A.Dufresne, and A. Gandini, "Modification of cellulose fibers with functionalized silanes: effect of the fiber treatment on the mechanical performances of cellulose-thermoset composites," Journal of Applied Polymer Science,vol.98, no.3, pp.974-984, (2005)

11. Munirah, M., Abdul Razak, R., \& Hassan, A. (2007). Characterization and Treatments of Pineapple Leaf Fiber Thermoplastic Composite For Construction Application. Fakulti Kejuruteraan Kimia Dan Kejuruteraan Sumber Asli Universiti Teknologi Malaysia Page 18.

12. Jayaramudu, J., B. Guduri, and A.V. Rajulu, Characterization of natural fabric Sterculia urens. International Journal of Polymer Analysis and Characterization, 2009. 14(2): p. 115-125.

13. Patrick, K., Onchiri, R.O. and Manguriu, G. (2019) Developing Suitable Proportions for the Production of Pineapple Leaf Fibers Reinforced Normal Strength Concrete. Open Journal of Civil Engineering, 9, 185-194. https://doi.org/10.4236/ojce.209.93013

14. Chollakup, R., Tantatherdtam, R., Ujjin, S., \& Sriroth, K. (2011). Pineapple leaf fiber reinforced thermoplastic composites: Effects of fiber length and fiber content on their characteristics. Journal of Applied Polymer Science, 119(4), 1952-1960. doi:10.1002/app.32910

15. Arib, R. M. N., Sapuan, S. M., Ahmad, M. M. H. M., Paridah, M. T., \& Zaman, H. K. (2006). Mechanical properties of pineapple leaf fiber reinforced polypropylene composites. Materials \& Design, 27(5), 391-396. doi:10.1016/j.matdes.2004.11.

16. Yan, L., N. Chouw, and X. Yuan, Improving the mechanical properties of natural fibre fabric reinforced. epoxy composites by alkali treatment. Journal of Reinforced Plastics and Composites, 2012. 31(6): p. 425-437

17. Luo, S. and A. Netravali, Interfacial and mechanical properties of environment-friendly "green" composites made from pineapple fibers and poly (hydroxybutyrate-co-valerate) resin. Journal of Materials Science, 1999. 34(15): p. 3709-3719. 
18. Cao, Y., Shibata, S. and Fukumoto, I. 2006. Mechanical properties of biodegradable composites reinforced with bagasse fibre before and after alkali treatments. Composites Part A. Applied Science and Manufacturing. Page: 423-429.

19. Yan, L., Effect of alkali treatment on vibration characteristics and mechanical properties of natural fabric reinforced composites. Journal of Reinforced Plastics and Composites, 2012. 31(13): p. 887-896. 